\title{
Leukocytosis: a risk factor for myocardial infarction
}

This article was published in the following Dove Press journal:

Research Reports in Clinical Cardiology

3 May 2012

Number of times this article has been viewed

\section{Suman K Kotla \\ Department of Internal Medicine, Memorial Medical Center, \\ Johnstown, PA, USA}

Correspondence: Suman K Kotla Department of Internal Medicine, Memorial Medical Center, I086 Franklin Street, Johnstown, PA I5905, USA $\mathrm{Tel}+\mathrm{I} 8145343953$

Fax + I 8I45345123

Email sumankotla4@hotmail.com
Abstract: Myocardial infarction commonly results from atherosclerotic lesions in the coronary arteries. Approximately $5 \%$ of patients with acute myocardial infarction do not have atherosclerotic disease. In this case report, we present an unusual leukostatic complication in a patient with acute myeloblastic leukemia and extreme hyperleukocytosis who presented with an acute myocardial infarction that resolved after leukopheresis. Myocardial infarction as the initial presentation of acute leukemia has been reported only rarely.

Keywords: leukocytosis, myocardial infarction, leukostasis

\section{Introduction}

Myocardial infarction is the rise and/or fall of cardiac biomarkers (preferably troponin) with at least one value above the 99th percentile of the upper limit of normal and evidence of myocardial ischemia, with at least one of the following: symptoms of ischemia, changes indicative of new ischemia on electrocardiography (ECG), development of pathological Q waves on ECG, imaging evidence of new loss of viable myocardium, or new regional wall motion abnormality, commonly resulting from atherosclerosis. Approximately $5 \%$ of patients with acute myocardial infarction do not have atherosclerotic disease but have other causes of vessel narrowing, such as congenital coronary artery anomalies, coronary artery fistula, a high takeoff position from the coronary ostia, myocardial bridges, coronary artery aneurysms, emboli, coronary dissection, spasm, vasculitis, infectious disease, Kawasaki's disease, a metabolic disorders, metastatic disease, or substance abuse, as described in a review by Waller et al. ${ }^{1}$ The association between acute myocardial infarction and acute myeloid leukemia is rare, and the pathophysiological relationship is undefined. Here, we present an unusual leukostatic complication in a patient with acute myeloblastic leukemia and extreme hyperleukocytosis who presented with an acute myocardial infarction that resolved after leukopheresis. Apart from our case, there has been one reported by Cohen et al concerning a 56-year-old woman with extreme hyperleukocytosis who presented with acute myocardial infarction followed by encephalopathy, which improved after leukopheresis. ${ }^{2}$

\section{Case report}

A 75-year-old male presented to the emergency room with chest pain and intermittent loss of vision for the previous two days. His past medical history included well controlled hypertension. Initially, he was evaluated at a different facility for the 
abovementioned symptoms. The chest pain was mainly retrosternal, graded $4 / 10$, nonradiating, and with no other associated symptoms. His pain improved with sublingual nitroglycerin. His ECG showed ST segment elevation in the inferior leads, and he had a troponin I of 2.62. He was transferred to our facility for possible cardiac catheterization. He was free of chest pain at our facility. An ECG obtained at our facility showed Q waves in leads 3 and AvF, (Figure 1), which was indicative of an old versus new infarct. He had an elevated troponin I of $27.95 \mathrm{ng} / \mathrm{mL}$ (normal $<0.01 \mathrm{ng} / \mathrm{mL}$ ) and creatine kinase $\mathrm{MB}$ of $122.9 \mathrm{ng} / \mathrm{mL}$ (normal 0-6.6 ng/mL). Routine blood work revealed a white blood cell count of $262 \times 10^{3} / \mu \mathrm{L}$, with $71 \%$ blasts, hemoglobin $8.7 \mathrm{~g} / \mathrm{dL}$, hematocrit $26 \%$, platelet count $59 \times 10^{3} / \mu \mathrm{L}$, and serum potassium of $9.8 \mathrm{mmol} / \mathrm{L}$ (pseudohyperkalemia). Repeated troponin I was 40.44. Hematology, oncology, nephrology, and cardiology consultations were obtained, and the patient was transferred to the intensive care unit. A flow cytometry report showed immature monomorphic blast cells expressing CD117, HLA-DR, CD11b, CD33, and CD14 while lacking CD34 expression, consistent with acute monocytic type (M5B) myeloid leukemia. Cardiac catheterization was deferred by the cardiologist due to his medical condition; thus, a computed tomographic scan of his chest was performed and showed marked coronary artery calcification. Aspirin was not started due to profound thrombocytopenia, but he was started on a beta-blocker. Leukopheresis was performed, and subsequently the white blood cell count and troponin I level trended down (Table 1). An echocardiogram was significant for an ejection fraction of $50 \%$ with no wall motion abnormalities. It was hypothesized that the patient's presentation of acute myocardial infarction was secondary to leukostasis from extreme leukocytosis in acute myeloid leukemia. After leukopheresis, a remission induction protocol was initiated, and the patient was discharged on a beta-blocker.

\section{Discussion}

Acute myeloid leukemia is the most frequently occurring form of acute leukemia in adults. ${ }^{3}$ It is a stem cell disorder of the hemopoietic system. In the majority of patients with acute myeloid leukemia, the initial symptoms are fever, weakness, night sweats, infections, and bleeding. Myocardial infarction as the initial presentation of acute leukemia has been reported rarely in the literature. Atherosclerosis accounts for $95 \%$ of cases of acute myocardial infarction, and the other $5 \%$ is attributable to nonatherosclerotic causes. In connection with acute leukemia, the following triggering mechanisms for acute myocardial infarction have been identified: disseminated intravascular coagulation, ${ }^{4-6}$ leukostasis syndrome, ${ }^{2}$ myocardial infiltration, ${ }^{7}$ and hemorrhage into the myocardium or intima of the coronary arteries. ${ }^{8}$

Acute myeloid leukemia may predispose patients to a hypercoagulable state, such as disseminated intravascular coagulation, which has been reported in patients with a promyelocytic type of acute myeloid leukemia in only a couple of case reports, ${ }^{2,5,6}$ but was not the cause in our case. In addition to coronary artery calcification, leukostasis secondary to hyperleukocytosis played a significant role in the manifestation of acute myocardial infarction in our case. Thus far, only one case has been reported in the literature. Hyperleukocytosis occurs in $8.5 \%$ of acute leukemia patients. Hyperleukocytosis results in decreased tissue perfusion, due to its deleterious effect on blood viscosity, and increases the incidence of acute myocardial infarction as reported in the literature. ${ }^{9}$

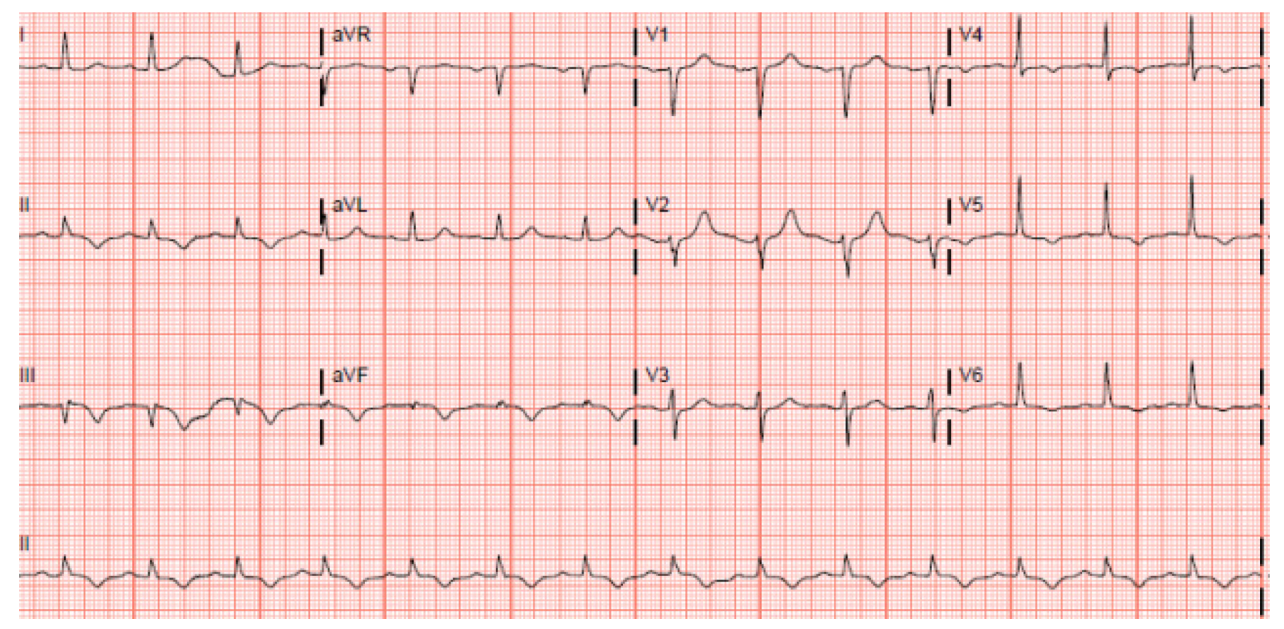

Figure I Electrocardiogram showing sinus rhythm, normal axis, $Q$ waves in lead 3 and AvF diagnostic for old versus new infarct, and T wave inversions in lead 2, 3, and AvF. 
Table I Leukocyte count and troponin levels before and after leukopheresis

\begin{tabular}{ll}
\hline Leukocyte count & Troponin I level \\
\hline $262 \times 10^{3} / \mu \mathrm{L}$ & $27.95 \mathrm{ng} / \mathrm{mL}$ \\
& $40.44 \mathrm{ng} / \mathrm{mL}$ \\
& $15.11 \mathrm{ng} / \mathrm{mL}$ \\
After first cycle of leukopheresis & \\
$183 \times 10^{3} / \mu \mathrm{L}$ & $8.62 \mathrm{ng} / \mathrm{mL}$ \\
After second cycle of leukopheresis & \\
$132 \times 10^{3} / \mu \mathrm{L}$ & $0.71 \mathrm{ng} / \mathrm{mL}$ \\
After third cycle of leukopheresis & \\
$5.6 \times 10^{3} / \mu \mathrm{L}$ & $0.01 \mathrm{ng} / \mathrm{mL}$ \\
$\begin{array}{l}\text { After induction chemotherapy and at time } \\
\text { of discharge } 2.0 \times 10^{3} / \mu \mathrm{L}\end{array}$ & \\
\hline
\end{tabular}

Leukocytes are larger and stiffer than erythrocytes and platelets, and their large spherical morphology is greater than the internal diameters of the capillaries. Capillary transit of leukocytes is difficult, so the microvascular circulation is more susceptible to slowing or even momentary occlusion when granulocyte plugging occurs. Clinically, leukostasis can be suspected in patients with unexplained fever, respiratory failure, and cerebral dysfunction because the brain and lungs are the two most commonly affected organs in leukostasis syndrome due to their microvasculature. Due to the larger diameter of the coronary arteries, leukostasis without any predisposing atherosclerotic lesion has never been reported to cause a significant myocardial infarction. Atherosclerosis is generally asymptomatic until the stenosis exceeds $70 \%$, which decreases myocardial perfusion. Past studies have shown that lesions less than $50 \%$ are more prone to rupture than large lesions. Superimposed calcification with hyperleukocytosis can cause decreased perfusion to the coronary arteries, as in our case. ${ }^{2}$ Our patient did not undergo cardiac catheterization, but a computed tomographic scan was significant for marked coronary artery calcification. Following leukopheresis, the patient's troponin level trended down, and he was asymptomatic. After reviewing the risks and benefits, the patient was offered remission induction therapy after the third day of admission, and he was discharged in a hemodynamically stable condition.

\section{Conclusion}

This case represents a rare association between acute myocardial infarction and acute myeloid leukemia. Furthermore, it provides evidence that leukostasis secondary to extreme leukocytosis can cause significant coronary artery occlusion. This phenomenon usually responds to leukopheresis if there is no superimposed atherosclerotic plaque rupture.

\section{Disclosure}

The authors report no conflicts of interest in this work.

\section{References}

1. Waller BF, Fry ET, Hermiller JB, Peters T, Slack JD. Nonatherosclerotic causes of coronary artery narrowing - Part 1. Clin Cardiol. 1996;19(6): 509-512.

2. Cohen Y, Amir G, Da'as N, Gillis S, Rund D, Polliack A. Acute myocardial infarction as the presenting symptom of acute myeloblastic leukemia with extreme hyperleukocytosis. Am J Hematol. 2002;71(1):47-49.

3. Jachmann-Jahn U, Cornely OA, Laufs U, et al. Acute anterior myocardial infarction as first manifestation of acute myeloid leukemia. Ann Hematol. 2001;80(11):677-681.

4. Candelpergher G, Suzzi GL, Visona A, Buchberger R. Acute myocardial infarct as the first manifestation of acute myeloid leukemia. Description of an anatomo-clinical case. G Ital Cardiol. 1980;10(10): 1403-1407. Italian.

5. Lisker SA, Finkelstein D, Brody JI, Beizer LH. Myocardial infarction in acute leukemia. Report of a case in a young man. Arch Intern Med. 1967;119(5):532-535.

6. Solomons HD, Stanley A, King PC, Plenaar N, Atkinson PM. Acute promyelocytic leukemia associated with acute myocardial infarction. A case report. S Afr Med J. 1986;70(2):117-118.

7. Dresdale DT, Spain D, Perez-Pina F. Heart block and leukemic cell infiltration of interventricular septum of heart. Am J Med. 1949;6(4):530-533.

8. Pervez H, Potti A, Mehdi SA. Challenging and unusual cases: Case 1. Simultaneous presentation of acute myelogenous leukemia and myocardial infarction. J Clin Oncol. 2003;21(7):1416-1417.

9. Ernst E, Hammerschmidt DE, Bagge U, Matrai A, Dormandy JA. Leukocytes and the risk of ischemic diseases. JAMA. 1987;257(17): 2318-2324.

\section{Publish your work in this journal}

Research Reports in Clinical Cardiology is an international, peerreviewed, open access journal publishing original research, reports, editorials, reviews and commentaries on all areas of cardiology in the clinic and laboratory. The manuscript management system is completely online and includes a very quick and fair peer-review system.

\section{Dovepress}

Visit http://www.dovepress.com/testimonials.php to read real quotes from published authors. 